\title{
APLICADOR DE HERBICIDAS COM PAVIOS DE CORDA*_ PRIMEIROS RESULTADOS DE CONTROLE
}

\author{
R.M. PRU DENTE ${ }^{1}$ \\ T. MATUO ${ }^{2}$ \\ ${ }^{1}$ Engen heiro Agrônomo. Superintendência da \\ Agricultura e Produção - SUDAP - Estação \\ Experimental de Boquim. 49.360, Boquim, \\ SE. \\ 2 Professor Assistente Doutor. Faculdade de \\ Ciências Agrarias e Veterinárias - UNESP. \\ 14.780 - Jaboticabal, SP. \\ * Pavcord.
}

\section{RESUMO}

Os aplicadores de herbicidas baseados em pavios de corda foram introduzidos e largamente aceitos nos EUA a partir de 1978, devido a sua grande simplicidade, baixo custo operacional e economia do herbicida.

Um protótipo fabricado com material inteiramente nacional, montado sobre duas rodas de bicicleta, tracionado pelo homem, tendo uma barra de 2 metros de comprimento, foi desenvolvido pelo Departamento de Defesa Fitossanitária da

Faculdade de Ciências Agrárias e Veterinárias de Jaboticabal- UNESP e submetido a um ensaio preliminar.

A área estava uniformemente coberta com vegetação natural, com altura média de $55 \mathrm{~cm}$ e a maioria das plantas daninhas em estádio de maturação das sementes. $\mathrm{O}$ aplica- dor foi deslocado à velocidade de $2,7 \mathrm{~km} / \mathrm{h}$, com consumo médio de 9,3 litros de calda por hectare, tendo aplicado diluições de glyphosate em água, nas proporções de 1:2, 1:4 e 1:6 (produto comercial: água) e comparado à pulverização convencional tratorizada, efetuada com velocidade de 4,2 $\mathrm{km} / \mathrm{h}$ e consumo de 4 litros de produto comercial com 310 litros de água por hectare.

As avaliações do controle foram efetuadas através da determinação da biomassa epígea por ocasião da aplicação aos 15 e 33 dias após, além da atribuição de notas aos 33 dias da aplicação.

Os resultados mostraram-se promissores para o protótipo, que pode desde já ser considerado um precioso instrumento para o manejo de plantas daninhas.

PALAVRAS-CHAVE: pavio de corda, herbicida, aplicador de herbicida. 


\section{SUMMARY}

ROPEWICKAPPLICATORFOR HERBICIDES. 1. FIRST WEED CONTROL RESULTS.

Rope wick applicators were introduced and widely accepted in the U.S.A. since 1978 due to its simplicity, low operational cost and reduced amount of herbicide used.

A first working built with material available in local market was assembled by the Department of Crop Protection of "Faculdade de Ciências Agrarias e Veterinárias - UNESP", Jaboticabal, Brazil, and preliminary results are reported in this paper. This model is mounted on two ordinary biclycle wheels, hand pulled, having $2 \mathrm{~m}$ wide boom with rope wicks. The experimental field was regular by covered with natural vegetation, average height of weeds about $55 \mathrm{~cm}$, the majority of weeds in seed maturation state. Rope wick applicator was run at $2.7 \mathrm{~km} / \mathrm{h}$, consuming about 9.3 liters liquid per hectare. The dilution tested were 1:2, 1:4 and 1:6 (partes of commercial Roundup: parts of water) and compared with conventional tract or boom spra yer applying 310 liter per hectare of solution contai ning 4 liters of commercial formulation, at the $4.2 \mathrm{~km} / \mathrm{h}$ speed.

Evaluations were carried out by assessing the top fresh weight of weeds at the application time and 15 and 33 days after. Score for weed control was attributed at 33 days after application.

The results showed that the model of applicat or tested has a good potentiality and it may be a valuable tool for the weed management.

KEYW ORDS: rope-wick, herbicide, herbicide application.

\section{INTRO DUÇÃO}

Normalmente, o controle de plantas daninha feito com a utili zação do método de pulverização tratorizada tradicional. Este método, apesar do bom controle que oferece, tem as desvantagens de ter alto custo operacional por área devido a utilização de máquinas e implementos agrícolas caros, gastos com combustível, manutenção e substituição de peças. Por aplicar grande volume de herbicida e água diluente por área, indiscriminadamente, por toda a faixa de aplicação, desperdiça produto e contamina o meio ambiente, além de outras. Contrapondo-se ao princípio do método referido, foi aperfeiçoado nos EUA o método de distribuição de herbicidas sistêmicos em pós-emergência, utilizandose pavios de corda ("rope wick"). Este método proporciona grande economia de herbicida e de água como veiculo, por área, oferece seletividade de posição sem deriva e é de fácil operacionalização, inclusive dispensando, a nível de agricultor, regulagens e calibrações complicadas.

As vantagens oferecidas pelo método de aplic ação com pavios de corda tem-lhe proporcionado grande aceitação por parte dos agricultores nos EUA, a ponto de Wills \& McWorther (2) estimar que área tratada em 1980 naquele país com o aplicador "rope wick" excedera em "grande número" a área testada por todas as outras técnicas de tratamento em pósemergência. Esses autores também prevêem que cerca de $90 \%$ do glyphosate a ser aplicado em pós-emergência nos EUA, no período de 1980 a 1985, será complicadores de pavios de corda.

Dale (1) obteve bons resulta- 
dos de controle com diluições em água que variaram entre 0,07 e $0,035 \mathrm{~kg} / \mathrm{ha}$ de glyphosate, em áreas com moderada e alta infestação de capim-maçambará (Sorghum halepense L.) em soja. Além disso aumentou a produtivi dade da sojanos dois ensaios e reduziu em 93\% a biomassa do capim em um deles. As aplicações foram feitas 5 a $10 \mathrm{~cm}$ acima da cultura, na velocidade de $4 \mathrm{~km} / \mathrm{h}$ e consumo aproximadamente de 0,5 litro de solução por hectare.

Tendo em vista as vantagens do método e a redução do seu custo operacional por área, desenvolveu- se um protótipo de aplicador com pavios de corda no Departamento de Defes a Fitossanitária da Faculdade de Ciências Agrárias e Veterinárias - UNESP, Jaboticabal, construído totalmente com material nacional, o qual foi testado em ensaio preliminar para o controle de plantas daninhas.

\section{MATE RIAL E METODOS}

O protótipo é montado sobre duas rodas comuns de bicicleta, empurrado pelo homem, tendo em sua frente uma barra aplicadora de 2 metros de comprimento. Essa barra um cano PVC de $38 \mathrm{~mm}$ de diâmetro interno, no qual se acham introduzidas as extremidades de segmentos da corda especial (pavios), cuja porção central de $20 \mathrm{~cm}$ se encontra exposta. A solução do herbicida, por ação da capi lari dade e da pressão, é transferi da para as plantas a sere m controladas.

A área, por ocasião da aplicação dos tratamentos, se encontra va com vegetação natural uniforme, com altura média de 55 $\mathrm{cm}$, coberta com as seguintes espécies: apaga-fogo [Althernantera ficoidea
(L.) R.Br.] - 30\%, trapoeraba(Com ma na sp.) - 20\%, anileira (Indi gofera Hirsuta L.) - 15\%,capim carr apicho (Cenchus echinatus L.) - $10 \%$, picão-preto (Bidens pilosa L.) $10 \%$, guanx uma (Sida sp.) - 5\%, capimamargoso [Tríchachne in sularis L.) Nees] $5 \%$ e outras. A maioria das plantas daninhas se encontrava em estádio de matur ação das sementes.

Empregou-se o delineamento de blocos casualizados para se estudar os efeitos de três diluições do herbicida glyphosate $(\mathrm{N}$, fosfonome til-glicina), nas proporções de 1

2, 1:4 e 1:6 (volume do produto co mercial*/volume de água)aplicados com pavios de corda, compara das a teste munha (s/aplicação) e à pulverização tratorizada tradicional (4 litros de produto comercial/310 litros de água, aplicados com bicos 80.04 operados a $60 \mathrm{lb} / \mathrm{po12}$ ). As aplicações com pavios de corda foram feitas na velo cidade de $2,7 \mathrm{~km} / \mathrm{h}$ e a pulverização a $4,2 \mathrm{~km} / \mathrm{h}$. Em ambas, a faixa de aplic ação teve dois metros de largura. Cada tratamento foi repetido em 5 parcelas, cada uma com área total de $100 \mathrm{~m}^{2}$ e útil de $24 \mathrm{~m}^{2}$. Foram feitas três amos tragens: antes da aplic ação dos tratamentos e aos 15 e 33 dias após a aplicação. Em cada amos trage m foram retiradas duas amostras por parcela, da biomassa epíge a contida num retân gulo de 1,0 x 0,6 m. Anotaram-se os dados de peso do mate rial "in natura"** e seco após secagem em estufa a $70^{\circ} \mathrm{C}$. Posteriormente avaliaram-se os efeitos dos tratamentos através das porcenta -

* Roundup.

**Peso anotado logo após a colheita do material, ante s da seca gem. 
gens de umidade existente nas amos tras aos 15 e 33 dias. Estimaram-se também, através do critério de notas, os efeitos dos tratamentos aos 33 dias. Nesta estimativa, padronizou-se que a testemunha representaria $0 \%$ de controle e que o controle total seria de $100 \%$. Por fim, os dados de percentuais de umidade e de percentual de controle, este atribuído através de notas, foram transformados para arc sen $\sqrt{\mathrm{x} / 100}$ e analisados estatisticamen te.

Quanto ao clima, nos cinco dias que antecederam a instalação do ensaio, houve precipitação de $42 \mathrm{~mm}$ de chuva e nos últimos 20 dias choveu $12 \mathrm{~mm}$. A média de umidade relativa no período foi de $68,7 \%$ e a da temperatura $19,8^{\circ} \mathrm{C}$. Em nenhum dos fatores do clima ocorreram dados próximos a qualquer dos extremos críticos.

\section{RESULTADOS E DISCUSSÃO}

Nos Quadros 1 e 2 são mostra dos os pesos do material "in natura" e seco, respectivamente, encontrados antes da aplicação dos tratamentos e aos 15 e 33 dias após a aplicação. Observa-se que a área se encontrava uniforme quanto aos pesos do material verde e seco, por ocasião da amostragem inicial, não ten do mostrado diferenças significativas entre tratamentos em ambos os casos, todavia mostrando diferenças entre blocos, indicando que foi adequado o delineamen to adotado. No decorrer do ensai o, os pesos do material seco variaram, mas não diferi ram estatisticamente. Todavia os pes os "in nat ura", devido a ação dos tra tamentos, experimentavam variações significativas, mostrando que, aos
15 dias as maiores reduções de peso "in natura" foram causadas pelos efeitos das aplicações com pavios de corda com diluições 1:2, 1:6 e pulverização, embora as duas primeiras não diferissem de 1:4. Já aos 33 dias, os efeitos das aplicações sobre a variação do peso "in natura", equipararam-se nas parcelas aplicadas, mas todas elas diferiram da testemunha.

No Quadro 3 são mostrados, respectivamente, os percentuais de umidade e de controle de plantas daninhas. Estes resultados diferem dos observados no Quadro 1 e são mais objetivos quanto aos efeitos dos tratamentos sobre as plantas daninhas. Observa-se que aos 15 dias os tratamentos pavio $1: 2$ pavio $1: 6$ não diferiram da pulverização, mas vieram a diferir desta aos 33 dias. Acredita-se que pelo fato do protótipo quase não atingir as plantas daninhas que se encontram encobertas, estas aparentaram ter sofrido apenas um retardamento do desenvolvimento, mas, posteriormente, contribuíram para aumento da umidade e melhoria do aspecto geral das amostras, a tal ponto que as diluições 1:2 e 1:6 passaram a diferir da pulverização. Estes resultados coincidem com os da anàlise dos percentuais de controle, expressos através de notas atribuídas ao aspecto geral das plantas daninhas e demonstram que todas as diluições aplicadas diferiram da testemunha e reduziram,em pelo menos $60 \%$, a umidade das plantas tratadas.

Ressalte-se que a população de plantas infestantes se encontrava em estádio avançado e crescida, e que algumas espécies presentes são consideradas de difícil controle, que explica o fato de até a pulverização não ter oferecido percentual de controle superior a $85 \%$, 
Quadro 1. Médias e resultados estatísticos dos efeitos de métodos de aplicaçōes e de 4 diluiçōes de glyphosate sobre o peso da biomassa epígea "in natura" de plantas daninhas. Jaboticabal, 1982 .

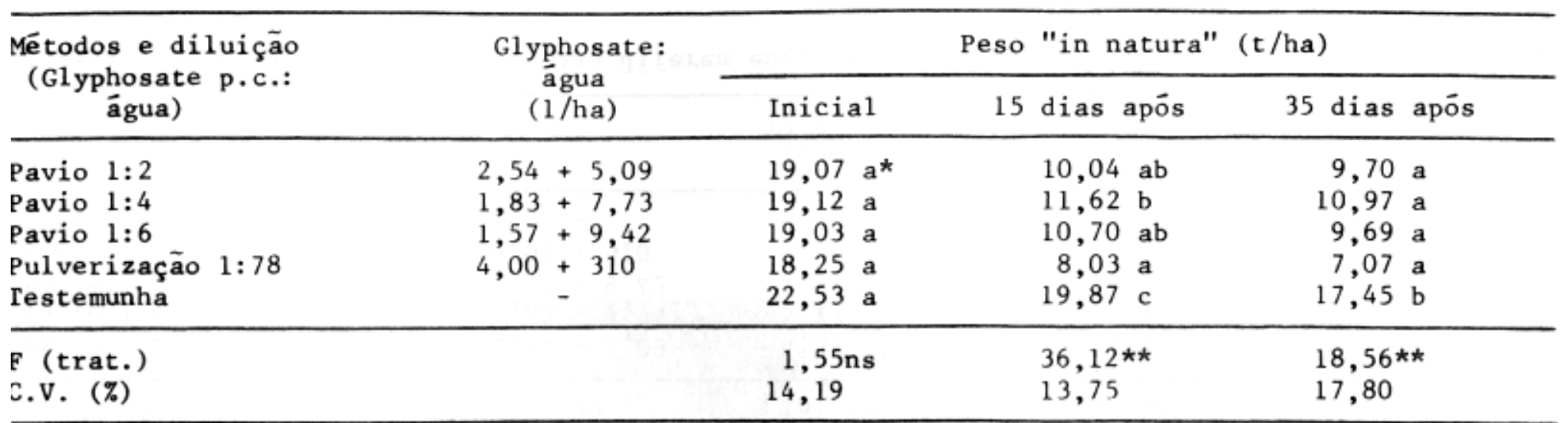

* Médias seguidas de pelo menos uma letra igual não diferem entre si pelo teste de Tukey a $5 \%$. 
Quadro 2. Médias e resultados estatísticos dos efeitos de métodos de aplicação e de 4 diluições de glyphosate sobre o peso da biomassa epígea seca de plantas daninhas. Jabotica ba1, 1982 .

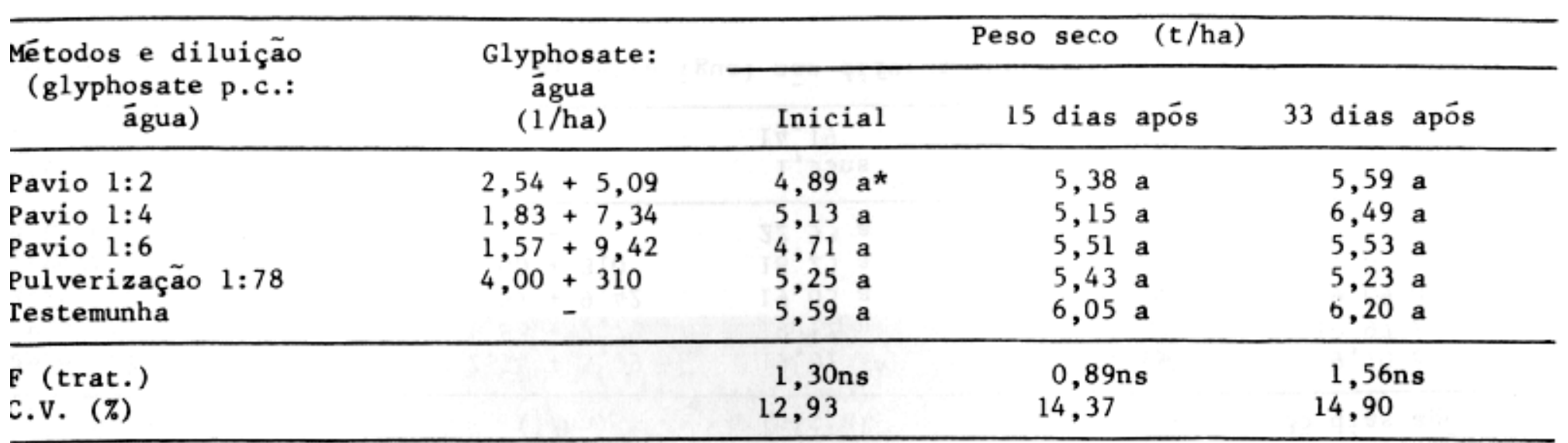

* Médias seguidas da mesma letra não diferem entre si pelo teste de Tukey a $5 \%$. 


\begin{tabular}{|c|c|c|c|c|c|}
\hline \multirow{2}{*}{$\begin{array}{c}\text { Métodos de diluição } \\
\text { (glyphosate p.c.: } \\
\text { ägua) }\end{array}$} & \multirow{2}{*}{$\begin{array}{l}\text { Glyphosate } \\
\text { p.c.: água } \\
\quad(1 / \mathrm{ha})\end{array}$} & \multicolumn{3}{|c|}{$\%$ de umidade } & \multirow{2}{*}{$\frac{\% \text { de controle } 1}{33 \text { dias após }}$} \\
\hline & & Inicial & 15 dias apōs & 33 dias após & \\
\hline $\begin{array}{l}\text { Pavio } 1: 2 \\
\text { Pavio } 1: 4 \\
\text { Pavio } 1: 6 \\
\text { Pulverização } 1: 78 \\
\text { Testemunha }\end{array}$ & $\begin{aligned} 2,54 & +5,09 \\
1,83 & +7,34 \\
1,57 & +9,42 \\
4,00 & +310 \\
& -\end{aligned}$ & $\begin{array}{l}73,63 \mathrm{a}^{2} \\
73,28 \mathrm{a} \\
75,20 \mathrm{a} \\
72,08 \mathrm{a} \\
75,28 \mathrm{a}\end{array}$ & $\begin{array}{l}46,27 \mathrm{ab} \\
55,43 \mathrm{bc} \\
47,43 \mathrm{ab} \\
31,29 \mathrm{a} \\
69,39 \mathrm{c}\end{array}$ & $\begin{array}{l}40,10 \mathrm{~b} \\
39,72 \mathrm{~b} \\
41,48 \mathrm{~b} \\
24,22 \mathrm{a} \\
63,97 \mathrm{c}\end{array}$ & $\begin{array}{l}48,4 \text { b } \\
50,4 \text { b } \\
45,4 \text { b } \\
85,0 \text { a } \\
-\end{array}$ \\
\hline $\begin{array}{l}\mathrm{F}(\text { trat. }) \\
\text { C.V. }(\%)\end{array}$ & & $\begin{array}{l}1,96 \mathrm{~ns} \\
2,26\end{array}$ & $\begin{array}{l}10,79 * * \\
11,92\end{array}$ & $\begin{array}{c}22,78 * * \\
9,40\end{array}$ & $\begin{array}{c}29,42 * * \\
6,48\end{array}$ \\
\hline
\end{tabular}

1 Média de notas estimadas de 0 a $100 \%$ por 4 avaliadores.

2 análise estatística aplicada aos dados transformados para arc sen $\sqrt{\mathrm{x} / 100}$.

As médias seguidas de pelo menos uma letra igual não diferem entre si pelo teste de Tukey a $5 \%$. 
com base nas notas atribuída s. Também com base neste critério, a pulverização diferiu das aplicações com pavios de corda, todavia estas não diferiram entre si, e mostram que o métod o com pavios de corda é eficiente no controle em pós-emergência das plantas daninhas, tendo oferecido média de $56 \%$ do controle obtido com a pulverização. Dentre as diluições aplicadas com pavios de corda, a diluição 1:6 destacou-se como a mais econômica e ofereceu $59 \%$ do controle oferecido pela pulverização apesar de, comparada a esta, tenha aplicado $60,75 \%$ menos de produto herbicida e $95,5 \%$ menos de volume de solução por área.

Acredita-se que o número de plantas não atingidas na aplicação com pavios de corda tendera a ser sempre menor a cada aplicação, pois, a própria cobertura vegetal morta favorecera o controle das plantas daninhas. O método com pavios de corda permite o estabelecimento de um programa de controle de plantas daninhas, constituindo-se num excelente instrumento de manejo.

Outro ponto que deve ser estudado é com relação a capacidade operacional do aplicador com pavios de corda. Este, apesar de nas condições do ensaio tenha sido operada a $2,7 \mathrm{~km} / \mathrm{h}$, quando em condições de infestação intermediária ou pequena, é bem provável que possa ser deslocado a velocidades maiores, sem prejuízo da eficiência, podendo exceder a capacidade de campo efetiva de $0,54 \mathrm{ha} / \mathrm{h}$ atingido neste ensaio. E também provável, que em jornadas de trabalho diário, o seu rendimento efetivo seja favorecido pela maior facilidade de manobras, abastecimento e por não requerer regulagens e calibrações muitas vezes demoradas, além- de outros fatores, em relação a pulveri zação tratorizada tradi cional.

De modo geral, o aplicador de herbicidas com pavios de corda mostrou-se bastante promissor, principalmente por se tratar do primeiro protótipo. Os resultados sugerem, entre outros, a necessidade de reali zação de ensaios que pesquisem se o menor percentual de controle oferecido pelo método com pavios de corda é compensado pelos seus menores custos de investimento e de aplicação.

\section{AGRA DECIMENTOS}

Os autores agradecem em especial ao técnico agrícola Gilson José Leite pela valiosa colaboração em todas as etapas de execução do ensaio; ao torn eiro José Carlos Biondi pelas sugestões e auxílio na construção do protótipo; as Indústrias Monsanto S/A pelo apoio financeiro prestado. Agrade cem também aos Srs. Ademar F. Minati e Manuel Chinelatto da Dívisão Textil da Rhodia S/A e Tapetes S. Carlos Ltda., respectivamente pela colaboração prestada.

\section{BIBLI OGRAF IA}

Dale, J.E. A non-mechanical system of herbicide application with a rope wick. PANS, 25(4): $431436,1979$.

Wills, G.D. \& McWhorter, C. G. Developments in post emergence herbicides applicators.

Outlook on Agricultu re, 